\title{
ArgVis: Structuring Political Deliberations Using Innovative Visualisation Technologies
}

\author{
Areti Karamanou ${ }^{1}$, Nikolaos Loutas ${ }^{1,2}$, and Konstantinos Tarabanis ${ }^{1}$ \\ ${ }^{1}$ Information Systems Lab, University of Macedonia, \\ 156 Egnatia Street, 54006 Thessaloniki, Greece \\ \{akarm, nlout, kat\} @uom.gr \\ ${ }^{2}$ National University of Ireland, Galway, Digital Enterprise Research Institute, \\ IDA Business Park, Lower Dangan, Galway, Ireland \\ nikos. loutas@deri.org
}

\begin{abstract}
Argumentation, having its roots back to ancient years, is used in many aspects of everyday life, such as law, politics, education and decision making. Argument Visualisation Tools serve the need of visualizing natural language's argumentations, targeting in the elimination of the traditional community sites' disadvantages such as the lack of expressiveness. This paper presents ArgVis, an argument visualization tool, which drives the development of structured dialogues in an uncomplicated manner, without demanding from the users to hold any special technical or argumentation skills. ArgVis structures argumentations in interactive graphs that comprise: Issues, Positions, Arguments and Counterarguments. One of ArgVis' innovations relies on the ability to integrate information with relevant, user-generated content from similar tools and sites by exporting data in a machine-readable format using the SIOC ontology.
\end{abstract}

Keywords: e-democracy, argumentation, deliberation, argument visualization, e-consultation, e-participation, semantics.

\section{Introduction}

Throughout the centuries numerous efforts have been made in order to generate acceptable frameworks, collections of rules and guidelines that aim to precisely describe the process of real-life argumentation. Argumentation is " a verbal and social activity of reason aimed at increasing (or decreasing) the acceptability of a controversial standpoint before a rational judge" [6]. The roots of argumentation trace back to the Greek Antiquity. Ancient Greeks recognized the existence of three main arts of discourse: rhetoric, logic or dialectic, and grammar also known as the "Trivium" [7]. Aristotle was one of the first to refer to the existence of arguments, thus providing the first formal study of logic [2]. Other important milestones in the history of argumentation include Anselm's ontological argument in his Proslogion [1], Descartes' ontological argument [4] and Wigmore's Chart Method to analyse the large number of evidence that may be conducted in a legal case [24]. A more recent approach is Toulmin's schema with six elements of a persuasive argument: claim, grounds, warrant, backing, qualifier, and rebuttal [20]. Toulmin's work, “although innovative 
in its day, [...] appears somewhat inflexible in the light of later work on defeasible reasoning and argumentation schemes" [3].

During the last decade the interest in deliberative democracy is steadily growing [11] and notions such as e-Democracy [18] and e-Participation [21] have become very popular. In terms of strengthening the government-citizen relations, OECD [16] has recognized three main relations that frame the processes of e-Government. These relations include: (a) Information, (b) Consultation, (c) Active participation.

There are a large number of online tools and applications designed to enhance e-Democracy activities that range from weblogs and alert mechanisms to more sophisticated consultation platforms [22]. However, the majority of these tools face the problem of being inappropriate for supporting discussions that efficiently contribute to the purposes of their users, such as the design of the argumentations and the interactions among their elements [5]. Moreover, tools such as webcasts, do not support interactivity with the users; users may only review rather than actively participate. Users usually face problems either due to their lack of experience using these kinds of tools or due to the tools' increased complexity. Particularly, in some of the traditional tools, such as discussion forums, the number of posts may vary from hundreds to thousands transforming their exhaustive overview to a real difficult and time consuming process. The high complexity of the discussion also makes it really hard for a viewer to obtain the central points of the discussion or come up with a conclusion. O'Keefe [15] mentions that although argumentation is concerned basically with the "making-arguments" process, the "having-arguments" process shouldn't be ignored. That implies that an argumentation tool should be able not only to support the creation of the discussion's arguments, but to enable the design of the interactions between the specific conversational moves [5].

Argument Visualisation Tools aim to promote near-natural-language presentation of arguments in a simple and clear way. They allow users to participate in structured and consistent argumentations by providing a friendly, intuitive and easy-to-use user interface. They may serve educational needs, (e.g. improvement of critical thinking) or aim to enhance the decision making processes of private companies and governments alike.

This paper presents ArgVis, an Argument Visualisation Tool that eliminates the traditional tools" disadvantages mentioned above. ArgVis serves as a "bridge" to integrate and present the different elements in a "visual" deliberation, in a way that everyone, regardless of their ICT and literacy skills, are able to participate.

The rest of the paper is structured as follows: Section 2 reviews other existing Argument Visualisation Tools and puts them vis a vis ArgVis to identify their common characteristics as well as their differences. Afterwards, section 3 presents ArgVis in detail, describing its architecture and functionalities, providing details regarding its technical implementation. Finally, in section 4 we summarize the paper and discuss the experience we gained by implementing and using ArgVis.

\section{Related Work}

This section briefly presents the most commonly used Argument Visualisation Tools that have been developed to serve various purposes. Some of them support a graphical 
representation of the argumentation, while others use linear, monolithic presentation methods similar to traditional forums.

AcademicTalk supports synchronous online educational argumentation based on the dialogue game theory, a theory that presents models with dialogue practices.

aMap was implemented to prove that it is possible for a web-based Argument Visualisation Tool to support the presentation of complex arguments in a unequivocal format.

Argumed is the descendant of Argue!. It recognizes three types of elements in argumentations: assumption, reason, and attack which are graphically presented.

Argumentations manages online argumentations and supports reusability of arguments to avoid their repetition in different debates.

Argumentative is an open source software to view and manipulate "assumptions", "reasons", "objections" and "helpers" using a tree-formed and easy to navigate view.

Araucaria is a software tool to analyse arguments in a diagrammatic form using a simple interface using. The arguments are saved in XML format.

Athena project was mainly implemented for educational reasons for both argument analysis and production. It includes two separate modules: Athena Standard for the design of argumentation and Athena Negotiator for the argumentation's decision analysis.

Belvedere aims to support the development of argumentation skills to young students. It supports several presentation forms such as hierarchical ones, graphs and tables.

Compendium is a software tool that provides a flexible user interface for managing the connections between visualised information and ideas during argumentation.

ConvinceMe was designed for educational needs to help students "structure, restructure, and assess their knowledge about often controversial situations 1 ".

Debategraph is an online tool that allows users to view a discussion's elements in a text or graphic form called "debate map". Users can create argumentations and add new arguments, and also publish, share, reuse and crosslink between their argumentations.

Debatewise supports online, realistic argumentations about several types of subjects such as religion and sports.

Dialaw is a dialogical model of legal justification [10]. It is a two-player game allowing its players to express their views in a tree mode and decide whether they agree or disagree.

Digalo is an educational argument visualisation tool used in classes for collaborative learning.

eDialogos is a project designed to support consultation processes in order to cooperate in "designing and implementing policies for the City". It incorporates three different tools: electronic surveys, e-signatures, and e-deliberation.

Parmenides is a software tool developed to allow structured argument over a proposed course of action. Arguments are stored in a Database for further analysis, with aim to recognise the weaknesses and advantages of the discussions' subjects.

Rationale uses argument maps to help students learn to analyse and think critically.

Reason!Able is a an educational-purposed tool. It supports the implementation of complex dialogues which it transforms in a plainer diagrammatic from.

\footnotetext{
${ }^{1} \mathrm{http}: / / \mathrm{www}$. soe.berkeley.edu/ schank/convinceme/index.html
} 
Theseus is used by students to develop their critical thinking skills. It supports a "thought tree" which consists of the questions that need to be answered, their answers, and the questions that arise from the answers and test their strength.

Truthmapping is a conversational tool which presents argumentations as simple conversations. The users' comments are formulated so as to eliminate optical complexity by avoiding repetitive posting of previous arguments. Table 1 provides an overview of the tools' features.

Table 1. Argument Visualisation Tool's overview

\begin{tabular}{lll}
\hline AV Tool & Purpose & URL \\
\hline AcademicTalk & Educational & $\begin{array}{l}\text { http://www.londonmet.ac.uk/ltri/research/projects/at. } \\
\mathrm{htm}\end{array}$ \\
\hline aMap & $\begin{array}{l}\text { Educational, } \\
\text { Policy Issues }\end{array}$ & $\mathrm{http} / / / \mathrm{www}$. amap.org.uk/ \\
& &
\end{tabular}

Argue!, Argumed General http://www.ai.rug.nl/ verheij/aaa/index.htm

\begin{tabular}{|c|c|c|}
\hline Argumentations & General & http://www.argumentations.com/ \\
\hline Argumentative & General & http://argumentative.sourceforge.net/ \\
\hline Araucaria & General & $\begin{array}{l}\text { http://www.computing.dundee.ac.uk/staff/creed/resea } \\
\text { rch/araucaria.html }\end{array}$ \\
\hline Athena & Educational & http://www.athenasoft.org/ \\
\hline Belvedere & Educational & http://www.pitt.edu/ suthers/belvedere/ \\
\hline Compedium & General & http://compendium.open.ac.uk/institute/ \\
\hline ConvinceMe & Educational & $\begin{array}{l}\text { http://www.soe.berkeley.edu/ schank/convinceme/in } \\
\text { dex.html }\end{array}$ \\
\hline Debategraph & General & http://www.debategraph.org \\
\hline Debatewise & General & http://www.debatewise.com/ \\
\hline Dialaw & $\begin{array}{l}\text { Legal justifica- } \\
\text { tion }\end{array}$ & http://cli.vu/ lodder/dialaw/ \\
\hline Digalo & Educational & http://dunes.gr/ \\
\hline eDialogos & Policy Making & http://www.samos-dialogos.gr/ \\
\hline Parmenides & Policy Issues & http://cgi.csc.liv.ac.uk/ katie/Parmenides1.html \\
\hline Rationale & Educational & http://austhink.com/ \\
\hline Reason!Able & Educational & http://www.goreason.com \\
\hline Theseus & Educational & http://www.skymark.com/Theseus/overview.asp \\
\hline Truthmapping & General & http://truthmapping.com/index.php \\
\hline
\end{tabular}

A common problem that traditional tools (e.g. Discussion Boards) face is the lack of expressiveness during the argumentation process. That means that identifying the central opinions or which opinion supports/opposes others through thousands of users' posts may be a really time consuming process. Driving structured dialogues with specific types of elements is ArgVis's solution to this barrier.

Another problem that some tools face is the argumentations' review. For example, the users need to spend a lot of time in order to review all the posts of an extended argumentation. ArgVis overcomes this problem by using visual representation of arguments and their relationships obtaining a highly expressive character. 
Structured dialogues and visual representation of dialogues are not innovative techniques in the field of Argument Visualisation. Apart from ArgVis, other Argument Visualisation Tools (e.g. Debategraph) support the construction of argumentations that lean on specific, visualised types of elements as well. However, a problem that may arise from the use of structured dialogues is the one of their complexity. For example, Debategraph identifies 11 different types of elements that constitute a complete argumentation. A user not familiar with Debategraph and argumentation theories may find it difficult to decide which type of elements best corresponds to his opinion. In contrast with Debategraph, ArgVis identifies only five different types of elements in an argumentation: Map, Issue, Position, Argument and Counterargument.

Table 2. Argument Visualisation Tools comparison

\begin{tabular}{|c|c|c|c|c|c|c|c|}
\hline AV Tool & Graph & $\begin{array}{l}\text { Interactive } \\
\text { Graph }\end{array}$ & $\begin{array}{l}\text { Structured } \\
\text { Dialogues }\end{array}$ & Free & $\begin{array}{l}\text { Open } \\
\text { Source }\end{array}$ & $\begin{array}{l}\text { Group Argumen- } \\
\text { tation }\end{array}$ & SIOC \\
\hline AcademicTalk & $\checkmark$ & $\checkmark$ & $\checkmark$ & N/A & $x$ & $\checkmark$ & $x$ \\
\hline aMap & $\checkmark$ & $x$ & $\checkmark$ & $\checkmark$ & $x$ & $\checkmark$ & $x$ \\
\hline Argue!Argumed & $\checkmark$ & $\checkmark$ & $\checkmark$ & $\checkmark$ & $x$ & $x$ & $x$ \\
\hline Argumentations & $x$ & $x$ & $x$ & $\checkmark$ & $x$ & $\checkmark$ & $x$ \\
\hline Argumentative & $\checkmark$ & $\checkmark$ & $\checkmark$ & $\checkmark$ & $\checkmark$ & $x$ & $x$ \\
\hline ArgVis & $\checkmark$ & $\checkmark$ & $\checkmark$ & $\checkmark$ & $\checkmark$ & $\checkmark$ & $\checkmark$ \\
\hline Araucaria & $\checkmark$ & $x$ & $\checkmark$ & $\checkmark$ & $\checkmark$ & $x$ & $x$ \\
\hline Athena & $\checkmark$ & $\checkmark$ & $x$ & $\checkmark$ & $\checkmark$ & $x$ & $x$ \\
\hline Belvedere & $\checkmark$ & $\checkmark$ & $\checkmark$ & N/A & N/A & $x$ & $x$ \\
\hline Compendium & $\checkmark$ & $x$ & $\checkmark$ & $\checkmark$ & $\checkmark$ & $x$ & $x$ \\
\hline ConvinceMe & $\checkmark$ & $x$ & $\checkmark$ & $\checkmark$ & $\checkmark$ & $x$ & $x$ \\
\hline Debategraph & $\checkmark$ & $\checkmark$ & $\checkmark$ & $\checkmark$ & $x$ & $\checkmark$ & $x$ \\
\hline Debatewise & $x$ & $x$ & $x$ & $\checkmark$ & $x$ & $\checkmark$ & $x$ \\
\hline Dialaw & $\checkmark$ & $x$ & $\checkmark$ & $x$ & $x$ & $\checkmark$ & $x$ \\
\hline Digalo & $\checkmark$ & $\checkmark$ & $\checkmark$ & $\checkmark$ & $x$ & $\checkmark$ & $x$ \\
\hline eDialogos & $x$ & $x$ & $x$ & $x$ & $\checkmark$ & $\checkmark$ & $x$ \\
\hline Parmenides & $x$ & $x$ & $\checkmark$ & $\checkmark$ & $x$ & $x$ & $x$ \\
\hline Rationale & $\checkmark$ & $\checkmark$ & $\checkmark$ & $x$ & $x$ & $x$ & $x$ \\
\hline Reason!Able & $\checkmark$ & $\checkmark$ & $\checkmark$ & $x$ & $x$ & $x$ & $x$ \\
\hline Theseus & $\checkmark$ & $\checkmark$ & $\checkmark$ & $x$ & $x$ & $x$ & $x$ \\
\hline Truthmapping & $x$ & $x$ & $\checkmark$ & $\checkmark$ & $x$ & $\checkmark$ & $x$ \\
\hline
\end{tabular}

Recent research and development in the Semantic Web call for open platforms that share and interlink data coming from other sources. Towards this direction, ArgVis uses a SIOC ${ }^{2}$ exporter to release the content of argumentations in the form of structured, machine-processable RDF data. It though creates a set of RDF documents that describe each of the ArgVis argumentations (maps) and every post (all of the issues, positions and arguments/counterarguments) on them. SIOC is a popular lightweight ontology that facilitates the semantic interlinking of online communities such as blogs, forums, wikis etc. SIOC is aW3C recommendation ${ }^{3}$. Hence, ArgVis argumentation data can be easily reused, linked and mashed with related data that exist in

\footnotetext{
${ }^{2}$ http://www.sioc-project.org

${ }^{3}$ http://www.w3.org/2007/02
} 
other community sites. SIOC data export is an innovative characteristic in the filed of Argument Visualisation Tools that none of the rest of the tools support.

Table 2 summarizes the key characteristics of different Argument Visualisation Tools', including ArgVis. The characteristics derived from a list of key criteria that can be used for evaluating Argument Visualisation Tools such as the support of graph-based representation, interactive techniques, structured dialogues etc.

\section{ArgVis}

ArgVis is an Argument Visualisation Tool designed to systematize the argumentation process by visually representing structured arguments to construct political deliberations. It aims to encourage people, especially the younger generation who are very familiar with new technologies, to express their opinions and contribute ideas to existing argumentations and be actively involved and participate in policy making.

ArgVis' argumentation model capitalizes on the components of a dialogue as defined by IBIS [9]:

(a) Area or topic, "a task named by a trigger phrase".

(b) Issues, which "are brought up and disputed because different positions are assumed".

(c) Arguments, which "are constructed in defense of or against the different positions until the issue is settled by convincing the opponents or decided by a formal decision procedure".

Table 3. Elements of ArgVis tool

\begin{tabular}{|c|c|c|c|}
\hline ArgVis Element & Description & Stereotype & IBIS Element \\
\hline Map & The initial point of the argumentation. & & Area or Topic \\
\hline Issue & $\begin{array}{l}\text { A statement that arises from the graph of the } \\
\text { argumentation. Issues can be connected only } \\
\text { with the central topic of the graph. }\end{array}$ & & Issue \\
\hline Position & $\begin{array}{l}\text { A position taken in response to a specific } \\
\text { issue. }\end{array}$ & & - \\
\hline Argument & $\begin{array}{l}\text { A premise that supports a position, i.e. in order } \\
\text { to strengthen a statement. }\end{array}$ & & Argument \\
\hline Counterargument & $\begin{array}{l}\text { A premise that is posed against a position, i.e. } \\
\text { in order to weaken a statement. }\end{array}$ & & Argument \\
\hline
\end{tabular}

ArgVis' argumentations allow five different types of elements that directly map to IBIS components: Map, Issue, Position, Argument, and Counterargument (see Table 3 ). The argumentations are organised in interactive graphs which comprise of these interconnected components depicted by representative icons. For example, Argument elements are represented by a node which depicts a happy smiley, while Counterargument elements are represented by a node that depicts an angry smiley. It is a way to help users recognize the meaning of each element at a glance. 


\subsection{Users and Functionalities}

This section describes the types of users that may participate in Argvis's argumentations, and briefly presents its user interface and functionalities (Table 4).

ArgVis' users range from simple users, for example citizens, who desire to take part in the argumentations' in progress or to collect other people's opinion on particular subjects, to researchers or students who want to advance their techniques in the art of argumentation, and of course to policy and decision makers.

ArgVis supports three different types of users with different access permissions and privileges to the tool's functionalities, namely unregistered users, registered users, and administrators.

Unregistered users constitute the elementary user type and have limited choices. They are only allowed to review the argumentation graphs.

Registered users are the ones that have followed successfully the subscription process. They have the chance to navigate through the interactive argumentation graphs, create their own argumentation graphs, and participate in existing argumentations by adding argumentation elements supported by ArgVis.

Finally, administrators have additional privileges as compared to unregistered users, such as editing all kind of elements existing in the argumentations.

Actions concerning editing and deleting elements and graphs may be completed only by administrators or registered users who own these contributions. Actions related to the visual graph's layout and other interaction techniques are allowed to any kind of users.

The main screen (see Figure 1) of ArgVis is partitioned in two main spaces: the deliberation space which consists of the visualized graph of the argumentation and the controls space on the left, which includes the functionalities supported by ArgVis. The argumentation graph comprises of elements of the five different type visualized as nodes (see Table 3 ).

Table 4. ArgVis users' and administrators' privileges

\begin{tabular}{lccc}
\hline Action & Unregistered Users & Registered Users & Administrators \\
\hline Review Argumentations & $\checkmark$ & $\checkmark$ & $\checkmark$ \\
Start argumentation & $\mathbf{x}$ & $\checkmark$ & $\checkmark$ \\
Add Element & $\mathbf{x}$ & Only his own & $\checkmark$ \\
Edit Elements & $\mathbf{x}$ & Only his own & $\checkmark$ \\
Delete Elements & $\checkmark$ & $\checkmark$ & $\checkmark$ \\
Graph Interaction & & & $\checkmark$ \\
Techniques & & & \\
\hline
\end{tabular}

\subsubsection{The Controls Space}

The controls space includes two main components: Users' actions and graph controls (i.e. controls that offer graph interaction techniques). There are two ways to perform users' actions. The first one is to make a selection from the menu on the controls space. The second one is by right-clicking on the appropriate node from the graph. 


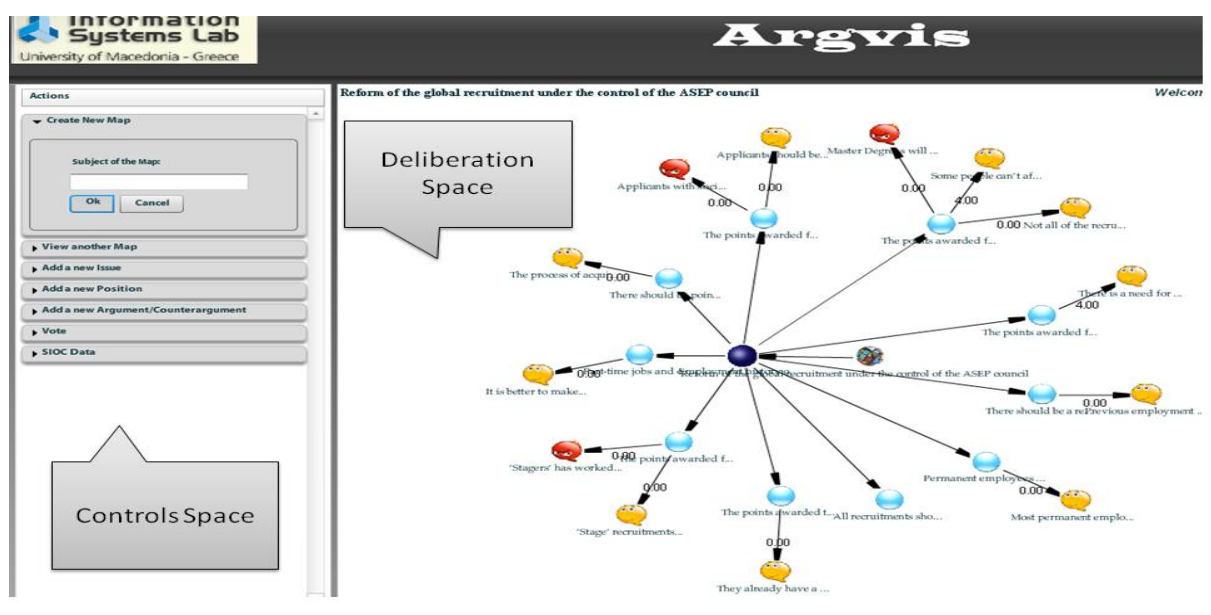

Fig. 1. ArgVis main screen

The controls space's user actions include:

- Creating a new argumentation graph on a desired topic.

- Navigating through available graphs, which allows browsing the topics list and reviewing the opinions stated.

- Adding issues, positions, arguments and counterarguments.

- Voting in order to expressing to what degree a registered user agrees or disagrees with an Argument or a Counterargument. The allowed values are integral numbers between one (disagree) to five (agree). The average values of the submitted votes are displayed on the links that connect the Arguments/Counterarguments with their positions.

- SIOC data export so that the contents of the argumentation can be extracted in a machine-understandable format using the SIOC ontology 4 .

The graph controls of the controls space enhance ArgVis' functional character. The graph controls include the functionalities that registered or unregistered users may use to alter the layout of the graph or to highlight specific elements of the graph. Specifically, graph controls include:

- Layout. Through the Layout control, the presentation scheme of the graph can be altered through a list of options: "SingleCycleCircle", "ConcentricRadial", "Hyperbolic", "Hierarchical", "ForceDirected", and "ISOM". Another option of the Layout control is the "Linklength" that defines the length of the links that connect the elements. The allowed values are from 0.00 to 600.00 . Lower values reduce the distance between the nodes of the graph, while higher values increase it. The last option is "Autofit", which resizes the graph to fit exactly on the screen.

\footnotetext{
${ }^{4} \mathrm{http}: / / \mathrm{www}$. sioc-project.org/ontology
} 
- View controls. They include two basic functionalities, the zoom one, and the scaling one. Zoom supports, in a scale of 0.25 to 2, the zoom in and zoom out actions. Scaling supports, in a scale of 0.5 to 2 , the increasing or decreasing of the elements' size.

- Degrees of separation. It can be used to define the depth of the argumentation's graph i.e. in what level elements of an argumentation will be represented. The values of the "Degrees of separation" range from 1, where only the main topic and its issues on the graph are presented, to 3, where all elements are presented.

\subsection{ArgVis Architecture and Implementation Details}

The framework of ArgVis can be separated into three main layers: the User Interface Layer (UI Layer), the Application Layer, and the Database layer (See Figure 2).

The User Interface Layer refers to the interaction between the users and the tool. It provides all the functionalities needed in order to transform the communication between the users and the system and the navigation through the tool into a simple and intuitive process.

The Application Layer operates as an intermediary between the User Interface Level and the Database Level. It implements all the functionalities supported by ArgVis, which are included in the control space as mentioned in the previous section. The implementation of the Application layer is based on Google's BirdEye RaVis ${ }^{5}$. BirdEye RaVis supports the development of complex data visualization interfaces for the analysis of relational data sets such as social networks. RaVis' library which is extended in ArgVis, is implemented for the Adobe Flex environment using MXML. In addition, ActionScript 3.0 is used to implement the client's logic.

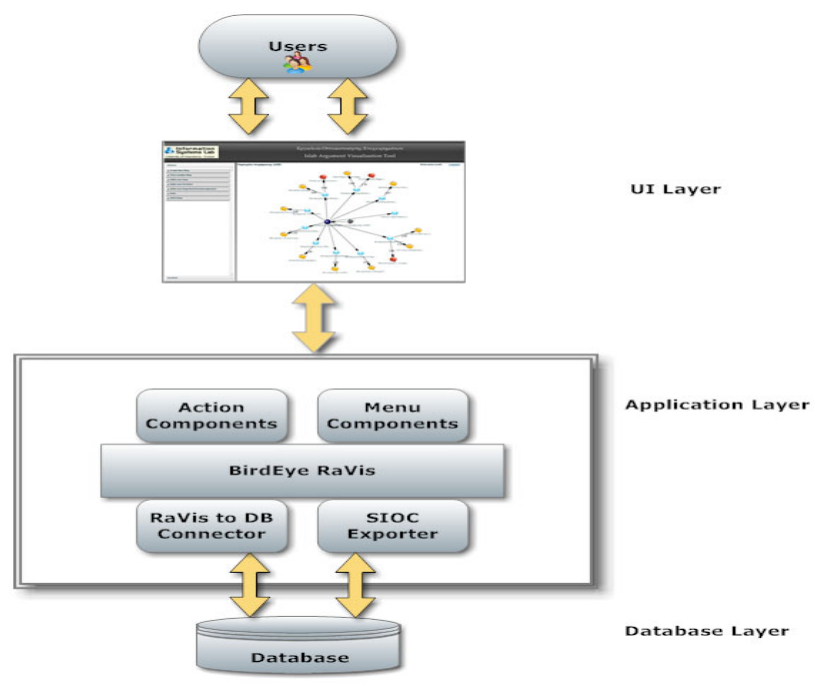

Fig. 2. ArgVis Layers

${ }^{5}$ code.google.com/p/birdeye 
ArgVis has used RaVis library to alter its User Interface, graphical layout and data representation, and the implementation's logic according to the needs of its services. A database (presented in the Database Layer) is embedded to the library in order to serve as a media of storage of visualized data.

Apart from $\mathrm{RaVis}$ extended libraries, the Application layer of ArgVis includes a Database Connector in order to interact with an implemented Database, as well as a the SIOC exporters which to convert the argumentations' elements to SIOC data using PHP scripts.

The bottom layer is the Database Layer. It implements the database which stores data definitions and data referring to the argumentations' elements, users' personal details etc. The Database is implemented using MySQL 5.1.49 and the access to/from it is developed using PHP scripts that collaborate with the MXML scripts. The whole application is installed on an Apache 2.2.16 Web server.

\section{Conclusions}

ArgVis is an Argument Visualisation Tool designed to be an easy-to-use, userfriendly and intuitive application that enhances argumentations as dynamic processes and eliminates many of the disadvantages and problems that traditional tools or other Argument Visualisation Tools face.

ArgVis supports an innovative functionality unique among other Argument Visualization Tools, the SIOC data export, which allows the cross-relation and mashing of ArgVis data with related data coming from other online community sites. None of the traditional or other Argument Visualisation Tools support it.

It supports well-defined structured dialogues as a way to increase the expressiveness of the argumentation's elements. Moreover, the structure of the argumentation graphs does not suppose that the user needs to have special critical thinking abilities so as novice users can take advantage of it. ArgVis dialogue's structure relies on IBIS well established dialogue theory predominating similar tools with undefined argument structure orientation. Additionally, its dialogue structure includes a limited number of elements (only five) reducing the complexity of the argumentations that tools like Debategraph (which uses 11 elements) face and making its argumentations more approachable to users.

ArgVis represents visually the argumentations that it hosts. Many similar tools, such as Argumentations, may support structured dialogues but not visually presented graphs. ArgVis' visual representation of arguments and their relations on the one hand enhances dialogues' expressiveness and on the other hand facilitates dialogues review by users. Moreover, the interaction techniques that ArgVis offers to the graphs, such as zooming and scaling, help the users to focus on specific parts of the argumentations eliminating the problem of complex, and difficult to read graphs.

Another advantage of ArgVis is the voting process, which offers the opportunity to select a preferred argument and express the agreement or disagreement with it. This may contribute to effectively come up with a general conclusion about the discussed topic by examining the highest and/or the lowest rated elements. 
Finally, ArgVis is the only Argument Visualisation Tool up to now that publishes the data of the argumentations that it hosts in an open, machine-processable format based on standardized ontology, i.e. SIOC.

Concluding, ArgVis features many attributes that give advantage to it related to other tools. Some of them can be found separately on other tools but not integrated in a single solution. For example, Truthmapping relies also on structured dialogues but does not support visualization and interactivity techniques. Another example is Debategraph that combines structured dialogues and visual representation but supports a variety of different argumentation elements that increase its complexity.

As part of our future work, in order to develop the next generation of ArgVis some improvements are planned. One is to allow users to search for the argumentation graphs of their interest using keywords, which will save time to users who are interested in specific matters. Moreover, it will be possible to group related topics into categories. Another improvement that will be implemented is to allow a registered user to create "private" graphs which will be accessible only to selected users. The owner will be able to invite other users by sending an invitation e-mail. Finally, an RSS feed will be developed in order to inform users on updates of selected argumentations of interest.

\section{References}

1. Anselm, S.: Proslogion. In: Charlesworth, M. (ed.) St. Anselm's Proslogion. OUP, Oxford (1965)

2. Aristotle, Roberts, R. (translator); Ross, W.D. (ed.): Rhetoric. Random House, New York (1954)

3. Cartwright, D., Atkinson, K.: Using Computational Argumentation to Support E- Participation. IEEE Intelligent Systems. Special Issue on Transforming E-government and Eparticipation through IT 24(5), 42-52 (2009)

4. Descartes, R.: Discourse on Method and The Meditations, translated with an introduction by F. Sutcliffe, Harmondsworth, Penguin (1968)

5. De Moor, A., Aakhus, M.: Argumentation Support: From Technologies to Tools. Communications of the ACM 49, 93-98 (2006)

6. van Eemeren, F.H., Grootendorst, R., Snoeck Henkemans, F., et al.: Fundamentals of Argumentation Theory. In: A Handbook of Historical Backgrounds and Contemporary Developments. Erlbaum, Mahwah (1996)

7. Joseph, S.M.: The Trivium: The Liberal Arts of Logic, Grammar, and Rhetoric. Paul Dry Books, Inc. (2002)

8. Heil, J.: First-Order Logic. Jones and Bartlett Publishers, Boston (1994)

9. Kunz, W., Rittel, H.W.J.: Issues as elements of information systems, Technical Report 0131, Institut für Grundlagen der Planung, University of Stuttgart, Stuttgart (1970)

10. Lodder, A.R.: DiaLaw: Levels, Dialog Trees, Convincing Arguments. In: van den Herik, H.J., et al. (eds.) The Twelfth Conference on Legal Knowledge Based Systems, JURIX, pp. 61-72. GNI, Nijmegen (1999)

11. Lupia, A.: Can Online Deliberation Improve Politics? Scientific Foundations for Success. In: Davies, T., Gangadharan, S.P. (eds.) Online Deliberation: Design, Research and Practice, pp. 59-69. CSLI Publications, Stanford (2009) 
12. Macintosh, A.: Characterizing E-Participation in Policy-Making. In: Proceedings of the 37th Hawaii International Conference on System Sciences, Big Island, Hawaii (2004)

13. Macintosh, A., Coleman, S., Lalljee, M.: E-Methods for Public Engagement: Helping Local Authorities communicate with citizens. Bristol City Council (2005), http://146.176.2.70/ITC/Documents/eMethods_guide2005.pdf

14. Macintosh, A., Gordon, T.F., Renton, A.: Providing Argument Support for E-Participation. Journal of Information Technology \& Politics 6, 43-59 (2009)

15. O'Keefe, D.: Two Concepts of Argument. Journal of the American Forensic Association 13, 121-128 (1977)

16. OECD: Citizens as Partners: Information, Consultation and Public Participation in Policymaking. OECD, Paris (2001)

17. OECD: Engaging Citizens Online for Better Policy- Making. OECD, Paris (2003)

18. Palvia, S.C.J., Sharma, S.S.: E-Government and E-Governance: Definitions/Domain Framework and Status around the World, Foundation of e-government, pp. 1-12 (2007)

19. Saeb $\varnothing, \varnothing$. ., Rose, J., Flak, L.S.: The shape of eParticipation: Characterizing an emerging research area. Government Information Quarterly 25(3), 400-428 (2008)

20. Toulmin, S.: The uses of argument. Cambridge University Press, Cambridge (1959)

21. Tambouris, E., Liotas, N., Tarabanis, K.: A Framework for Assessing eParticipation Projects and Tools. In: Proc. 40th Int. Conf. on System Sciences, Hawaii, p.90a (2007)

22. Tambouris, E., Macintosh, A., Coleman, S., Wimmer, M., Vedel, T., Westholm, H., Lippa, B., Dalakiouridou, E., Parisopoulos, K., Rose, J., Aichholzer, G., Winkler, R.: Introducing eParticipation. In: Tambouris, E. (ed.) DEMO-net The Democracy Network. DEMO-net booklet series, vol. (1). University of Macedonia (2007)

23. Walton, D.N.: Dialogue Theory for Critical Thinking. Springer, Heidelberg (1989)

24. Wigmore, H.J.A.: The principles of judicial proof as given by logic, psychology, and General experience and illustrated in judicial trials, 2nd edn. Little Brown, Boston (1931); reprint 2000, William S. Hein \& Co., Inc. (1913) 